\title{
The Effects of Cryotherapy on Knee Joint Position Sense and Force Production Sense in Healthy Individuals
}

\author{
by \\ Mariusz P. Furmanek ${ }^{1}$ Kajetan J. Stomka1, Andrzej Sobiesiak², \\ Marian Rzepko ${ }^{3}$, Grzegorz Juras ${ }^{1}$
}

\begin{abstract}
The proprioceptive information received from mechanoreceptors is potentially responsible for controlling the joint position and force differentiation. However, it is unknown whether cryotherapy influences this complex mechanism. Previously reported results are not universally conclusive and sometimes even contradictory. The main objective of this study was to investigate the impact of local cryotherapy on knee joint position sense (JPS) and force production sense (FPS). The study group consisted of 55 healthy participants (age: $21 \pm 2$ years, body height: $171.2 \pm 9 \mathrm{~cm}$, body mass: $63.3 \pm 12 \mathrm{~kg}$, BMI: $21.5 \pm 2.6$ ). Local cooling was achieved with the use of gel-packs cooled to $-2 \pm 2.5^{\circ} \mathrm{C}$ and applied simultaneously over the knee joint and the quadriceps femoris muscle for 20 minutes. JPS and FPS were evaluated using the Biodex System 4 Pro apparatus. Repeated measures analysis of variance (ANOVA) did not show any statistically significant changes of the JPS and FPS under application of cryotherapy for all analyzed variables: the JPS's absolute error $(p=0.976)$, its relative error $(p=0.295)$, and its variable error $(p=0.489)$; the FPS's absolute error $(p=0.688)$, its relative error $(p=0.193)$, and its variable error $(p=0.123)$. The results indicate that local cooling does not affect proprioceptive acuity of the healthy knee joint. They also suggest that local limited cooling before physical activity at low velocity did not present health or injury risk in this particular study group.
\end{abstract}

Key words: proprioception, kinesthesia, healthy knee joint, cooling.

\section{Introduction}

The term "proprioception" was initially proposed by Sherrington (1906). Currently, it is defined as "the afferent information arising from internal peripheral areas of the body, that contributes to postural control, joint stability (static positions and dynamic movement), and several conscious sensations" (Riemann and Lephart, 2002a). Proprioception plays an important role in neuromuscular control, a complex process of coordination, and in movement precision (Hübscher et al., 2010; Knoop et al., 2011). Hence, proprioception is considered to be a subset of the entire somatosensory system (Proske, 2015; Richie, 2001; Williams et al., 2001). Joint position sense, kinesthesia, and a sense of force (tension, resistance, or weight) are all components of proprioception (Riemann and Lephart, 2002a, 2002b). The growing knowledge regarding proprioception has initiated many positive changes in professional sport leading to the routine incorporation of the specific neuromuscular and proprioceptive exercises in athletic training (Caraffa et al., 1996; Chappell and Limpisvasti, 2008; Hewett et al., 2006; Kynsburg et al., 2010; Mandelbaum et al., 2005; Salles et al., 2015; Zebis et al., 2008). What is also important, an early detection of proprioception deficit and implementation of an appropriate

\footnotetext{
1 -Jerzy Kukuczka Academy of Physical Education in Katowice, Department of Human Motor Behavior, Katowice, Poland.

2 - University of Windsor, Department of Mechanical, Automotive E Materials Engineering, Windsor, Ontario, Canada.

3 - University of Rzeszow, Faculty of Physical Education, Rzeszow, Poland
} 
exercise/rehabilitation program can prevent functional instability of a joint and consequently its repetitive injury (Hewett et al., 2006; Laskowski et al., 2000; Lephart et al., 1998). Such exercise programs frequently involve the use of cryotherapy (Hubbard et al., 2004; Swenson et al., 1996).

Although, application of cryotherapy is relatively straightforward, much controversy and confusion remain regarding the understanding of how cryotherapy influences proprioception. A review of the literature revealed that results regarding the influence of cryotherapy on proprioception are contradictory and ambiguous (Costello and Donnelly, 2010; Furmanek et al., 2014). Many studies have shown that cooling has no influence on JPS (Costello and Donnelly, 2011; Dover and Powers, 2004; Hart et al., 2005; Khanmohammadi et al., 2011; LaRiviere and Osternig, 1994; Thieme et al., 1996; Wassinger et al., 2007); in contrast, other studies concluded that cryotherapy had a negative effect on JPS (Hopper et al., 1997; Oliveira et al., 2010; Uchio et al., 2003; Surenkok et al., 2008). Only two studies investigated the influence of cryotherapy on force production sense (Rubley et al., 2003; Tremblay et al., 2001). These studies, however, concluded that the perception of force was not affected by local cooling.

Cryotherapy consists of lowering the tissue temperature by withdrawing heat from the body to achieve an analgesic effect (Knight, 1995). The application of cold in clinical practices is meant to reduce swelling and inflammation, relieve muscle spasm and facilitate a better movement (Bleakley, 2004). The use of cold in healthy athletes increases the pain threshold, tissue viscosity, production of endorphins, testosterone, readiness for physical activity and general recovery from fatigue and stressful bouts of sports training (White and Wells, 2013). Typically, local cryotherapy is applied only over a joint (Costello and Donnelly, 2010; Furmanek et al., 2014). In this study, cryotherapy was used over a joint and muscles simultaneously. It was assumed that if cryotherapy influences proprioception, this particular application of cold could influence the receptors of both muscle spindles responsible for muscle length and Golgi tendon organs (GTO) responsible for muscle tension (Proske, 2005; Proske and Gandevia, 2012). This application could also influence the proprioceptive receptors located in the soft tissue. Therefore, in the present study, both the active-active reproduction of joint positioning, which is commonly called joint position sense (JPS), and force (re)production sense (FPS) were evaluated after cryotherapy treatment. Moreover, measurement of more than one aspect of proprioception allowed a better assessment of proprioception acuity. The JPS test determines the ability of a subject to perceive and reproduce a required (desired) joint angle (Brindle et al., 2010; Dover and Powers, 2003; Roberts et al., 2007; Wassinger et al., 2007), whereas the FPS test represents the ability to differentiate force generated by a muscle group (Docherty and Arnold, 2008; Grob et al., 2002; Knoop et al., 2011; Roberts et al., 2007; Rubley et al., 2003).

Complex mechanisms that control movement of a single joint under different temperatures reflect the importance and necessity of the topic of cryotherapy influence on the proprioception system, particularly in the context of clinical patients and athletic training. Based on the literature, we hypothesized that cryotherapy would adversely affect proprioception. Thus, the objective of this study was to determine the effects of locally applied cryotherapy on two aspects of proprioception, a knee joint position and force production sense.

\section{Methods}

\section{Participants}

Sixty healthy subjects (44 females and 16 males) voluntarily participated in the study. Individuals were excluded from the investigation if they had any motor, vestibular, or neuromuscular and orthopedic impairment, particularly sense disturbance within the knee joints, injury of the knee joints, damage or torn ligament (-s) within the knee joints, reconstruction of the knee ligament (-s), damage of the knee capsules, meniscus (-es), arthritis of the knee, inflammation, and contraindications to cryotherapy. Five subjects were excluded from data collection, because they presented one of the above exclusion criteria. The study group was randomly divided into two groups. The first group $(n=40)$ was subjected to cryotherapy and the second one $(n=15)$ constituted a control group. The anthropometric data of all participants included in the study are shown in Table 1 . The 
experimental methodology was approved by the Institutional Review Board and was performed in accordance with the ethical standards of the Declaration of Helsinki (Harriss and Atkinson, 2013). All of the participants signed an informed consent form before the investigation. All data were collected in the laboratory of Human Motor Behavior. The dominant lower limb was examined for all of the subjects. Limb dominance was defined according to the leg that subjects would normally use to kick a ball.

\section{Instrumentation}

The Biodex Multi-Join System, 4 Pro (Biodex Medical Systems, Inc., Shirley, NY, USA) was used for assessing JPS and FPS. The Biodex uses a specialized software package combined with a dynamometer, internal electrogoniometer, and a range of motion set switches, along with several limb attachments for testing. The Biodex is a valid and reliable instrument $\left(\mathrm{ICC}_{2, \mathrm{k}}=0.99\right)$ (Drouin et al., 2004). Taylor et al. (1991) obtained a high correlation for measuring static torque $(\mathrm{r}=$ 0.998 ) and angular position outputs $(r>0.999)$ using this instrument. Moreover, before the investigation, the interclass correlation coefficient $\left(\mathrm{ICC}_{2, \mathrm{k}}\right)$ was calculated for the JPS and FPS tests. To obtain reliable results, at least three repetitions were required for the JPS test $\left(\mathrm{ICC}_{2, \mathrm{k}}=0.980\right)$, two for the maximal isometric voluntary contraction $(\mathrm{MVC})$ test $\left(\mathrm{ICC}_{2, \mathrm{k}}=0.943\right)$ and five for the FPS test $\left(\mathrm{ICC}_{2, \mathrm{k}}=0.954\right)$.

Skin surface temperature was measured using $\mathrm{K}$ type thermocouples ( $\mathrm{NiCr}-\mathrm{NiAl}$, TTE 426$\mathrm{K}$ with a $2 \times 0.13 \mathrm{~mm}$ diameter and a length of 1.5 $\mathrm{m})$. The thermocouples were connected to the 4channels, and digital read-out (YC-747UD) of $0.1^{\circ} \mathrm{C}$ $\pm 0.1 \%$ accuracy. These temperatures were recorded by means of PC software Temp Monitor_S2, ver. 1.016. The frequency of measurement was $1 \mathrm{~Hz}$.

\section{Design and Procedures}

Before each measurement session, the Biodex calibration was verified. The torques were gravity corrected using Biodex software, taking into account the weight of the investigated limb. All of the measurements were conducted in standard conditions before and immediately after cryotherapy. The data collection occurred during a single session and consisted of two consecutive measurements of the block randomized JPS and FPS proprioception tests. The subjects were comfortably seated in the Biodex chair with the seatback tilted to $85^{\circ}$, the head and neck supported, and the seat adjusted with its edge located approximately $3-4 \mathrm{~cm}$ from the popliteal fossa with the chains hanging freely with a knee flexion of $90^{\circ}$ (Figure 2). The axis of the Biodex rotation shaft was aligned precisely with the knee flexing-extension axis crossing through the lateral femoral condyles on a sagittal plane. The shank strap was covered with foam to reduce cutaneous sensory inputs. The lower edge of the strap was secured above the line between the malleolus. To eliminate visual input, the subjects were blindfolded. The test instructions were verbally communicated to the subject before the test procedure. To familiarize the subjects with the entire procedure and apparatus, they participated in preliminary trials. To stabilize the body, each subject was fastened with two straps across the chest and one strap across the pelvis. Additionally, during the FPS test, a thigh strap was used. Before the measurements for each subject, an individual range of motion of the dominant limb knee joint was set between $0^{\circ}$ (full extension) and $90^{\circ}$ of knee flexion (Figure 2). The entire investigation lasted approximately $45 \mathrm{~min}$ for each subject.

\section{Evaluation of joint position sense}

The subjects performed active reproduction of the active motion JPS test, as it is a reliable method of knee position sense measurements (Olsson et al., 2004), and it provides relatively more afferent information compared to the passive JPS test (Smith et al., 2013). The test protocol used in this investigation was in full agreement with the recommendation of knee testing by Olsson et al. (2004). The starting position was $90^{\circ}$ of knee flexion. Once the subject was ready, they moved their limb at a low velocity $\left(\sim 10^{\circ} / \mathrm{s}\right)$ from extension to a randomly assigned angle of $60^{\circ}, 45^{\circ}$, or $30^{\circ}$ of knee joint flexion. Then, after the participant reached the required position, the Biodex held this position for $8 \mathrm{~s}$. During this time, the subject had to memorize the position with particular emphasis on the knee joint. Next, the Biodex released the lever until the starting position was reached again. The participants were then asked to actively reproduce this predetermined target angle with the same limb. Once the participant reached the estimated angle position of the knee joint, they signaled that fact by pressing a button with their dominant hand. The rest period between trials was $15 \mathrm{~s}$. The 
entire active JPS test was comprised of 9 trials. Based on the average of three repetitions for each angle, three variables (absolute, relative and variable errors) were calculated that characterized the accuracy and precision of the measurements (Brindle et al., 2010; Olsson et al., 2004; Selfe et al., 2006). The absolute error (JPS $\mathrm{AE}_{\text {) }}$ was the average error in the three trials, ignoring the direction of the error; the relative error (JPSRE) was the average error in the three trials, taking into account the direction of the error; and the variable error (JPSvE) was the standard deviation of the three relative error measurements (Olsson et al., 2004).

\section{Evaluation of force production sense}

The starting position was set at $45^{\circ}$ of knee flexion. This position was chosen, since it was in the middle of the range of motion between $0-90^{\circ}$. The maximal isometric voluntary contraction (MVC) of the knee muscle extensors was measured at the onset of FPS testing. The subjects were asked to extend their lower leg in the knee joint as hard as possible without any movement for $5 \mathrm{~s}$. The subjects were instructed to give a maximal effort for the entire duration of both trials. The rest periods between the trials amounted to $30 \mathrm{~s}$. In the next five consecutive trials, the participants were asked to produce $50 \%$ of their MVC. After the first attempt of force production sense, each subject received feedback of the force torque that they had used. The rest periods between the trials were $10 \mathrm{~s}$. The entire FPS test consisted of seven trials. The results from the FPS test were the variables calculated as the difference between torque forces achieved by the subject and the standard measurement, which was $50 \%$ of the mean MVC from both trials expressed in $\mathrm{Nm}$. The variables were also expressed by percentages and were referred to as a force production error (FPE). This error was calculated for each of the five trials and for each individual subject according to Equation 1.

$$
F P E=\frac{(F S-50 \% M I V C)}{50 \% M I V C} 100(\%)
$$

Similar to the JPS test, based on the percentage force production error, three dependent variables were calculated: the absolute error $\left(\mathrm{FPS}_{\mathrm{AE}}\right)$, which was the average error in the five trials, ignoring the direction of the error; the relative error (FPSRE), which was the average error in the five trials, taking into account the direction of the error; and the variable error (FPSve), which was the standard deviation of the five relative error measurements.

\section{Cryotherapy application}

Two multiuse, commercial cold gel-packs (3M Nexcare Cold/Hot Maxi) were applied for $20 \mathrm{~min}$. This particular duration and method of cryotherapy application was chosen because it is considered safe and is commonly used in Physiotherapy practice (Bleakley and Davison, 2010; Dykstra et al., 2009; Swenson et al., 1996). One gel-pack covered the knee joint with the center of the cold gel-pack over the patella of the dominant limb; the other gel-pack covered the quadriceps muscle and was placed perpendicularly on the frontal part of the thigh in such a way that one edge of the quadriceps gel-pack made contact with the knee gel-pack (entire size was $40 \times 60 \mathrm{~cm}$, surface area $1200 \mathrm{~cm}^{2}$, mass $1546 \mathrm{~g}$, heat capacity 4.46 $\mathrm{kJ} / \mathrm{kg} / \mathrm{K})$. The cold-packs were applied simultaneously and were secured with an elastic bandage $(15 \mathrm{~cm} \times 1.5 \mathrm{~m}$, width $\times$ length) without compression. Each gel-pack was inserted into a thin cotton pouch to prevent frostbite of the skin. The mean temperature was $-2^{\circ} \pm 2.5$. During cryotherapy application, subjects were seated in a comfortable position with $\sim 15^{\circ}$ of knee flexion; the lower limb was supported by the Biodex lever. The control group maintained the same position but without any cryotherapy. The proprioception measurements were conducted immediately after the cryotherapy packs were removed.

\section{Temperature measurements}

During the investigation, four surface temperatures were measured using thermocouples: $T_{1}$ (quadriceps muscle) was secured on the skin of the one-third distal part of the rectus femoris muscle; $T_{2}$ (knee joint) was secured on the skin in the middle area above the tuberosity of the tibia and below the patella of the dominant knee joint; $\mathrm{T}_{3}$ (cold-packs temperature) was attached to the surface of the gel-pack under the cotton cover and elastic bandage; and $\mathrm{T}_{4}$ (ambient temperature) measured the laboratory temperature during the investigation.

The temperature curves $\left(T_{1}, T_{2}, T_{3}, T_{4}\right)$ shown in Figure 3 are averages of the individual temperature curves for all of the participants in all trials (40 individuals in total).

To compare the surface temperatures of the quadriceps muscle $\left(T_{1}\right)$ and knee joint $\left(T_{2}\right)$ 
before and after cryotherapy, a mean temperature was determined for three periods: the initial temperature, the cryotherapy temperature, and the final temperature for each individual subject. These temperatures were calculated based on the area under the temperature curve of the quadriceps muscle and knee joint according to Equation 2.

$$
T_{m}=\frac{1}{\left(t_{k}-t_{p}\right)} \sum_{i=0}^{f} \frac{\left(T_{i+1}+T_{i}\right)}{2}\left(t_{i+1}-t_{i}\right)
$$

where:

$T_{i}$-temperature of $i$-measurements $\left({ }^{\circ} \mathrm{C}\right)$

$T_{m}$ - mean temperature $\left({ }^{\circ} \mathrm{C}\right)$

$f$-number of temperature measurements

$t_{i}$ - time of $i$ - measurements (s)

$t_{p}-$ initial time (s)

$t_{k}-$ final time $(s)$

\section{Statistical Analysis}

To determine the homogeneity of the investigated groups, the Hotelling's T-squared test was applied for the independent trials. The reliability of the proprioception test measured using the Biodex system was calculated using the intraclass correlation coefficient (ICC) described by Shrout and Fleiss (1979).

The dependent variables were tested for a normal distribution using the Shapiro-Wilk test. Descriptive statistics were used to calculate the mean and standard deviation. The homogeneity of variance within the tested groups was assessed using Cochran's C, Hartley's and Bartlett's tests. The assumption of sphericity was checked using the Mauchley's test. If the assumption was unfulfilled $(p<0.05)$, the improvement of Greenhouse-Geisser (G-G) and Huynh-Feldt (H-F) was used.

The mean temperatures (initial, cryotherapy, and final) were compared using analysis of variance ANOVA for repeated measures.

A 2 x 2 x 3 (group factor: cryotherapy/control $\mathrm{x}$ repeated factor: pre/post $\mathrm{x}$ three angular positions of $60^{\circ} / 45^{\circ} / 30^{\circ}$ ) repeated measure analysis of variance ANOVA was used to determine the influence of cryotherapy on JPS. A 2 x 2 (group factor: cryotherapy/control $x$ repeated factor: pre/post) repeated measure analysis of variance ANOVA was applied to detect the influence of cryotherapy on FPS. An ANOVA was conducted for each dependent variable: absolute (AE), relative (RE) and variable (VE) errors calculated both for JPS and FPS. For all of the analyses, statistical significance was set at $p<0.05$. To check for any significant differences, a post-hoc analysis (Bonferroni test) was used. STATISTICA software ver. 11 (StatSoft, Inc.) was used for all analyses.

\section{Results}

Taking into account age, body height, body mass and body mass index (BMI), the investigated groups (cryotherapy group vs. control group) were homogenous $\left(\mathrm{T}^{2}=2.4, \mathrm{~F}_{(4,50)}=0.58, p<\right.$ $0.679)$.

The initial average skin temperatures of the quadriceps muscle and knee joint were 30.4 $\pm 0.2^{\circ} \mathrm{C}$ and $29.5 \pm 0.9^{\circ} \mathrm{C}$, respectively. After $20 \mathrm{~min}$ of cryotherapy application (the average temperature of the gel-packs was $-2 \pm 2.5^{\circ} \mathrm{C}$ ), the surface quadriceps muscle temperature decreased by $17^{\circ} \mathrm{C}\left(\mathrm{F}_{(2,38)}=285, p<0.001\right)$, whereas the surface knee joint temperature decreased by $20.1^{\circ} \mathrm{C}\left(\mathrm{F}_{(2,38)}=\right.$ $460, p<0.001)$. The temperatures of the quadriceps muscle and knee joint remained statistically significant compared to the temperatures during the initial measurements $(p<0.001)$. The ambient temperature was constant throughout the entire investigation $\left(22.1 \pm 0.7^{\circ} \mathrm{C}\right)$. These temperature changes are depicted in Figure 1.

In the control group, the average surface quadriceps temperature was $30.7 \pm 1^{\circ} \mathrm{C}$, whereas the average surface knee joint temperature was 29 $\pm 1.3^{\circ} \mathrm{C}$. Those temperatures were constant throughout the investigation.

No significant differences between the pre and post JPS test using a repeated measures ANOVA were found in either the cryotherapy group or the control group for the absolute $\left(\mathrm{F}_{(1,53)}=\right.$ $0.01, p=0.976)$, relative $\left(\mathrm{F}_{(1,53)}=1.12, p=0.295\right)$, and variable errors $\left(\mathrm{F}_{(1,53)}=0.48, p=0.489\right)$. The ANOVA revealed a significant interaction between pre/post, cryotherapy/control and the angular position of the absolute error $\left(\mathrm{F}_{(2,106)}=3.83, p=0.025\right)$. The posthoc analyses did not reveal any significant differences. The main effect of the angular position of the relative error was significant $\left(\mathrm{F}_{(2,106)}=13.7, p\right.$ $=0.001$ ). The post-hoc analysis revealed significant differences between the targeted angular positions for the relative error (all $p$-values $<0.001$ ), (Figure 2). 


\section{Temperature changes over time}

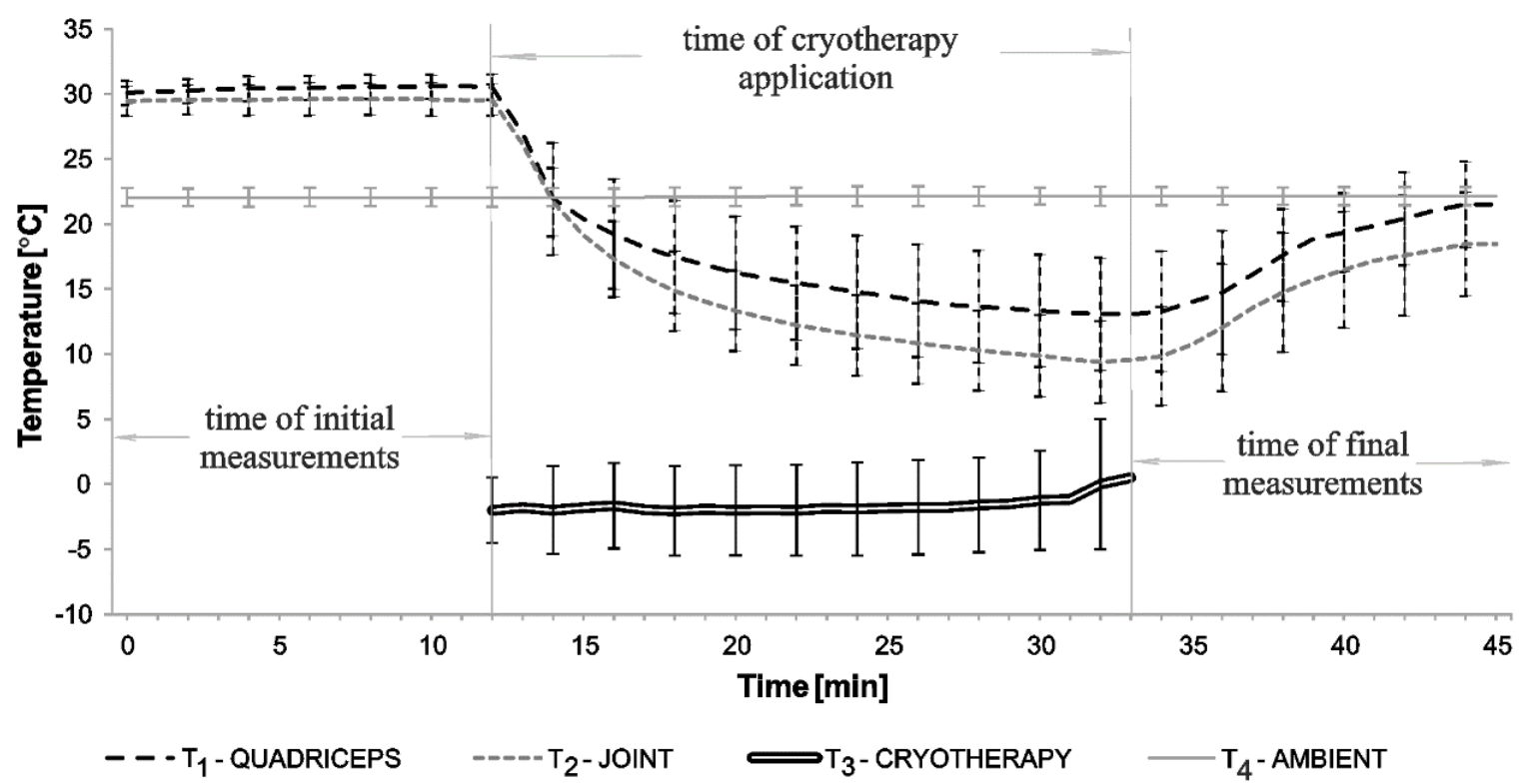

Figure 1

Mean and standard deviation of the temperatures collected during the investigation

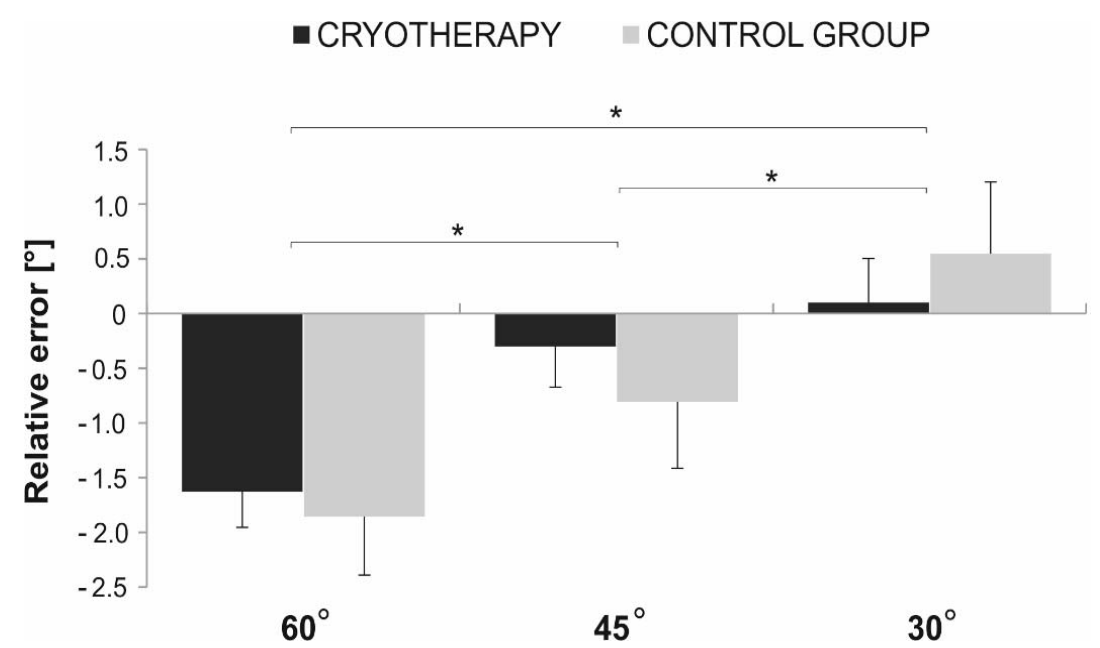

Figure 2

Mean and standard deviation of relative error for the cryotherapy and control groups 
Table 1

Characteristics of subjects participating in the study

\begin{tabular}{lccc}
\hline $\begin{array}{l}\text { Characteristic } \\
(\text { mean } \pm \mathrm{sd})\end{array}$ & Cryotherapy & Control & Total \\
\cline { 2 - 4 } & $\mathrm{n}=40$ & $\mathrm{n}=15$ & $\mathrm{n}=55$ \\
\hline Age $($ years $)$ & $21.4 \pm 1.6$ & $20.9 \pm 1.4$ & $21.2 \pm 1.6$ \\
\hline Height $(\mathrm{cm})$ & $171.3 \pm 9.2$ & $170.6 \pm 8.6$ & $171.2 \pm 8.9$ \\
\hline Weight $(\mathrm{kg})$ & $63.2 \pm 12.7$ & $63.5 \pm 11.6$ & $63.3 \pm 12.3$ \\
\hline BMI $\left(\mathrm{kg} / \mathrm{m}^{2}\right)$ & $21.4 \pm 2.5$ & $21.7 \pm 2.8$ & $21.5 \pm 2.6$ \\
\hline Limb dominance & R-36, L-4 & R-14, L-1 & R-50, L-5 \\
\hline Gender & F-30, M-10 & F-11, M-4 & F-41, M14 \\
\hline
\end{tabular}

$n$ - the size of the study group, sd - standard deviation, BMI-body mass index, $R$ - right, L - left, F- female, $M$ - male

Table 2

Mean absolute, relative, and variable errors of joint position sense and force production sense tests

\begin{tabular}{|c|c|c|c|c|}
\hline \multirow{3}{*}{ Outcome } & \multicolumn{4}{|c|}{ Absolute error } \\
\hline & \multicolumn{2}{|c|}{ Pre-test } & \multicolumn{2}{|c|}{ Post-test } \\
\hline & Cryotherapy & Control & Cryotherapy & Control \\
\hline JPS $60^{\circ}$ & $2.6 \pm 2.0$ & $1.6 \pm 1.6$ & $2.4 \pm 2.1$ & $2.9 \pm 1.7$ \\
\hline $\mathrm{JPS} 45^{\circ}$ & $2.2 \pm 1.6$ & $2.6 \pm 1.2$ & $2.8 \pm 2.1$ & $2.2 \pm 1.4$ \\
\hline JPS $30^{\circ}$ & $2.1 \pm 1.9$ & $2.9 \pm 2.1$ & $2.4 \pm 1.6$ & $2.7 \pm 1.7$ \\
\hline FPS \% & $16.3 \pm 12.4$ & $18.9 \pm 12.6$ & $17 \pm 10.5$ & $21.2 \pm 12.8$ \\
\hline \multirow{3}{*}{ Outcome } & \multicolumn{4}{|c|}{ Relative error } \\
\hline & \multicolumn{2}{|c|}{ Pre-test } & \multicolumn{2}{|c|}{ Post-test } \\
\hline & Cryotherapy & Control & Cryotherapy & Control \\
\hline $\mathrm{JPS} 60^{\circ}$ & $-1.8 \pm 2.8$ & $-1.8 \pm 2.8$ & $-1.8 \pm 2.8$ & $-1.8 \pm 2.8$ \\
\hline $\mathrm{JPS} 45^{\circ}$ & $-0.1 \pm 2.8$ & $-0.1 \pm 2.8$ & $-0.1 \pm 2.8$ & $-0.1 \pm 2.8$ \\
\hline JPS $30^{\circ}$ & $0.3 \pm 2.8$ & $0.3 \pm 2.8$ & $0.3 \pm 2.8$ & $0.3 \pm 2.8$ \\
\hline FPS \% & $-0.5 \pm 20.1$ & $-0.5 \pm 20.1$ & $-0.5 \pm 20.1$ & $-0.5 \pm 20.1$ \\
\hline \multirow{3}{*}{ Outcome } & \multicolumn{4}{|c|}{ Variable error } \\
\hline & \multicolumn{2}{|c|}{ Pre-test } & \multicolumn{2}{|c|}{ Post-test } \\
\hline & Cryotherapy & Control & Cryotherapy & Control \\
\hline JPS $60^{\circ}$ & $2.8 \pm 1.3$ & $2.8 \pm 1.3$ & $2.8 \pm 1.3$ & $2.8 \pm 1.3$ \\
\hline $\mathrm{JPS} 45^{\circ}$ & $2.0 \pm 1.0$ & $2.0 \pm 1.0$ & $2.0 \pm 1.0$ & $2.0 \pm 1.0$ \\
\hline $\mathrm{JPS} 30^{\circ}$ & $2.9 \pm 1.8$ & $2.9 \pm 1.8$ & $2.9 \pm 1.8$ & $2.9 \pm 1.8$ \\
\hline FPS $\%$ & $13.4 \pm 7.1$ & $13.4 \pm 7.1$ & $13.4 \pm 7.1$ & $13.4 \pm 7.1$ \\
\hline
\end{tabular}

JPS - joint position sense, FPS - force production sense 
No significant differences between the pre and post FPS test using a repeated measures ANOVA were found in either the cryotherapy group or the control group for the absolute $\left(\mathrm{F}_{(1,53)}=\right.$ $0.16, p=0.688)$, relative $\left(\mathrm{F}_{(1,53)}=1.73, p=0.193\right)$, and variable errors $\left(\mathrm{F}_{(1,53)}=2.45, p=0.123\right)$. Only the main effects of the pre/posttest for the relative $\left(\mathrm{F}_{(1,53)}=6.58, p=0.02\right)$ and variable errors $\left(\mathrm{F}_{(1,53)}=\right.$ $10.8, p=0.02$ ) were significant. However, the posthoc analyses did not reveal any significant differences. All of the results are shown in Table 2.

\section{Discussion}

The objective of this study was to investigate the influence of cryotherapy on proprioception. Two aspects of proprioception, the joint position sense (JPS) and the force production sense (FPS), were examined. No significant differences were found following cryotherapy application by means of cold gel-packs for $20 \mathrm{~min}$.

To our knowledge, this is the first investigation examining the effect of cryotherapy applied over the knee joint and the quadriceps muscle simultaneously. Such procedure has been used to influence receptors imbedded not only in soft tissue around the knee joint (e.g., Ruffini endings, Pacinian corpuscles, and free nerve endings), but also in muscles and tendons (e.g., muscle spindles and GTOs) (Williams et al., 2001). Proske (2005) emphasized that JPS was communicated mostly by muscle spindles. However, after cooling, none of these receptors underwent an adverse change in sensitivity indicating that the state of proprioception remained unaltered.

Therefore, the question of the effectiveness of the cooling methods used in this study arises. The 3 M Nexcare Cold Maxi gel-packs were used to decrease the temperature. The mean temperature of cryotherapy was $-2 \pm 2.5^{\circ} \mathrm{C}$, and as shown in Figure 3, the gel-packs maintained the temperature throughout the entire application. In clinical practice, the time of cryotherapy stretches between 10 to $45 \mathrm{~min}$ depending on modality, compression, localization and the area covered, thickness of fat, ambient temperature and the subject's sensitivity to cold (Dykstra et al., 2009; Kennet et al., 2007; Warren et al., 2004). Holcomb (2005) noticed that to prevent damage to the peripheral nerves, cryotherapy must never exceed $30 \mathrm{~min}$ of application. Therefore, $20 \mathrm{~min}$ duration was used in this study, and this particular time was enough to significantly cool $(p<0.001)$ the surface temperature of the knee joint $\left(20.1^{\circ} \mathrm{C}\right.$ mean decrease) and the quadriceps muscle $\left(17^{\circ} \mathrm{C}\right.$ mean decrease). The same duration of cryotherapy had been used in a number of previous investigations (Thieme et al., 1996; Tremblay et al., 2001; Wassinger et al., 2007).

Previous studies allowed researchers to assess how deeply the cryotherapy penetrated. For instance, the investigation conducted by Warren et al. (2004) showed that the knee intra-articular temperature after $30 \mathrm{~min}$ of cryotherapy (crushed ice) decreased on average by $3.3^{\circ} \mathrm{C}$, whereas surface temperature decreased by an average of $21.4^{\circ} \mathrm{C}$. The conclusion of Myrer et al. (1998) who applied in their study a 20-min treatment with an ice-pack (crushed ice) was a decreased intramuscular temperature (measured at a depth of $1 \mathrm{~cm}$ below the subcutaneous fat and skin) by 7.1 $\pm 4.1^{\circ} \mathrm{C}$. Moreover, Algafly and George (2007) demonstrated that nerve conduction velocity decreased by $17 \%$ when the surface temperature of the skin reached $15^{\circ} \mathrm{C}$, and when the temperature was $10^{\circ} \mathrm{C}$, nerve conduction velocity decreased to $33 \%$. Based on the results of the above investigations, it was assumed, in this work, that the applied cryotherapy was effective enough to cool the deep tissues of both the muscle and the knee joint and to reduce nerve conduction velocity. Furthermore, the data were collected immediately after the cryotherapy procedure when the temperature of the tissue remained significantly decreased $(\mathrm{p}<0.001)$.

The present results are in agreement with earlier investigations regarding the influence of cryotherapy on proprioception sense (Costello and Donnelly, 2011; Dover and Powers, 2004; Hart et al., 2005; Khanmohammadi et al., 2011; LaRiviere and Osternig, 1994; Rubley et al., 2003; Thieme et al., 1996; Tremblay et al., 2001; Wassinger et al., 2007). Despite the fact that different methods of cryotherapy were applied in all of the previous investigations, there were no adverse effects of cooling on proprioception. However, the results presented here are contrary to those presented by Olivieira et al. (2010), who conducted a similar study. They found that cryotherapy applied for 20 min impaired knee joint position sense in a healthy knee. Moreover, a deleterious effect appeared regardless of where the cryotherapy was used 
(muscle or joint). The cryotherapy was applied for $20 \mathrm{~min}$, but they used crushed ice bags (1200 g, surface area $500 \mathrm{~cm} 2)$. Yet, they did not measure the temperature of the cold modality or the temperature of the soft tissue where the cryotherapy was applied. It is also interesting to note that in their investigation, all of the subjects (n $=15$ ) overestimated the test position (knee JPS decreased $2.2^{\circ}$ immediately following cryotherapy); thus, the absolute and relative error had the same value. Divergent results to the present investigation were also reported by Hooper et al. (1997), Uchio et al. (2003), and Surenkok et al. (2008). In addition to the different methods of cryotherapy application (crushed ice, gel-pack, and ice water immersion), differences between studies may have resulted from the various proprioception protocol measurements (active, passive, and different joints), the use of different apparatuses and the soft tissue cooling time (from 5 to $30 \mathrm{~min}$ ). In the above described investigations, the JPS test was generally performed without other proprioception tests. Only Surenkok et al. (2008) conducted a one leg static balance test. However, no significant differences were found in this particular test after the cryotherapy application. It is worth noting that this team used the same gel-pack as in our study (3M cold gel-pack), but the authors also mentioned a lack of temperature measurements and a small sample size $(n=15)$ as their limitations; therefore, those results should be interpreted with caution.

Errors in the JPS test (absolute, relative, and variable) in this investigation were close to the error values presented in previous proprioception investigations (Brindle et al., 2009; Costello and Donnelly, 2011; Olsson et al., 2004). Olsson et al. (2004) emphasized that absolute error was the most reliable error as a proprioception measure. Hence, in our investigation, the absolute error was adopted as the most important measurement. Furthermore, most studies (Costello and Donnelly, 2011; Dover and Powers, 2004; Olsson et al., 2004; Surenkok et al., 2008) which analyzed a JPS test took into account the mean value from three trials for each angular position. In this study, the mean value from three repetitions was also used in addition to ensuring that each subject performed the entire trial as precisely as possible.

A detailed analysis of the JPS relative error revealed an interesting and important relationship from a methodological point of view (Figure 4). The lower the angle in the knee joint (increased tension of the soft tissue stabilizing joint, more muscle activity), the better the position sense of the knee joint. Moreover, the subjects overestimated when targeting the $30^{\circ}$ angular position $\left(0.1^{\circ}\right.$ for the cryotherapy group and $0.5^{\circ}$ for the control group), whereas they underestimated when targeting the $60^{\circ}$ angular position $\left(-1.6^{\circ}\right.$ for the cryotherapy group and $-1.9^{\circ}$ for the control group). Changes in the relative error when targeting the $45^{\circ}$ angular position corroborated this trend $\left(-0.3^{\circ}\right.$ and $\left.-0.8^{\circ}\right)$. The observed relationship confirmed that proprioception receptors were most sensitive for an angular position close to the anatomical range of motion in the knee joint ( Pincivero et al., 2001; Thieme et al., 1996).

In a review paper, Costello and Donnelly (2010) underscored that in investigations on proprioception, it was important to measure several aspects of this system. Thus, in this study, a force production sense test was conducted as well. A literature review showed that only two teams, Tremblay et al. (2001) and Rubley et al. (2003), conducted an investigation of force production sense after cryotherapy. The results of these studies unanimously supported the hypothesis that local cryotherapy did not adversely influence this aspect of proprioception. In this investigation, FPS, similar to JPS, was presented using three error values (FPSAE, FPSRE, and FPSVE) expressed as percentages. The mean absolute error after cryotherapy increased by $0.7 \%$, showing that more subjects underestimated the relative error by approximately $-1.5 \%$, whereas the variable error showed variability around the mean value of $11.2 \%$. All of the error differences were statistically non-significant ( $p>0.05$ ). These data agree well with Rubley et al. (2003), who also concluded that cryotherapy had no effect on precision (force variability) and force accuracy ( $p>$ 0.05) in finger forces, and Tremblay at al. (2001), who concluded that after local cooling, the discriminative performance remained similar at a level of from 4 to $10 \%$ in weight (threshold range, 0.11 to $0.26 \mathrm{~kg}$ ) using thigh muscles ( $\mathrm{p}=0.81$ ).

One could assume that under the particular procedures used in this study there was no effect of cryotherapy on both aspects of proprioception, because the shank movement also engages the hamstring group muscles which were 
not subjected to cryotherapy. At this point, it is worthwhile to recall the study conducted by Costello and Donnelly (2011). As cryotherapy, they used cold water $\left(14 \pm 1^{\circ} \mathrm{C}\right)$ immersion for $30 \mathrm{~min}$. Participants were immersed to the level of the umbilicus. Therefore, they cooled both agonist's and antagonist's muscles simultaneously. However, they found no evidence of knee joint position sense impairment following their cryotherapy protocol, suggesting that exposing hamstring muscle to cooling in this study would not affect the obtained results.

There are many sport competitions which take place in areas with excessively low temperatures. Moreover, frequently athletes are subjected to treatments that involve local lowering of the body temperature before and during physical activities. We believe that the results of our study support the notion that cryotherapy does not impair their proprioceptive abilities and does not compromise athletic performance.

There are, however, some limitations of our study. Only surface temperatures of the quadriceps muscle and the knee joint were measured. Also, only low velocity $(\sim 10 \stackrel{\%}{\mathrm{~s}})$ was used to conduct the active reproduction of the active motion JPS tests. In the future, it would be worthwhile to conduct the JPS test using different velocities after cryotherapy, thus replicating conditions as similar as possible to natural movement involved in athletes' competition. Finally, only a singular joint of healthy young participants was investigated, thus the results are relevant for this study group.

Evaluation of more than only one aspect of knee proprioception enhances proprioception acuity (Costello and Donnelly, 2010) and it seems to be more relevant to clinical practice (Docherty and Arnold, 2008; Riemann and Lephart, 2002a). It could be very important especially if one takes into account a proprioceptive system state as an injury risk prevention method. The results showed that there was no adverse effect on the evaluated aspects of knee proprioception under this particular cryotherapy procedure which is commonly used in practice. This study involved healthy young subjects, therefore the future extension of such investigations should include more diverse groups of professional athletes and clinical patients.

The results of this study allow to draw the practical conclusion that treatment using cryotherapy before physical activity is safe, taking into account active-active JPS with low velocity and the FPS aspects of proprioception in this particular study group. This statement may be very important in practice for both athletic training and physiotherapy.

\section{Acknowledgements}

This study was supported by statutory funds from the J. Kukuczka Academy of Physical Education in Katowice, Poland. The authors would like to thank Dr. Normand Teasdale for his help and comments on this article.

\section{References}

Algafly AA, and George KP. The effect of cryotherapy on nerve conduction velocity, pain threshold and pain tolerance. Br J Sports Med, 2007; 41: 365-369

Bleakley C, McDonough S, MacAuley D. The use of ice in the treatment of acute soft-tissue injury: a systematic review of randomized controlled trials. Am J Sports Med, 2004; 32: 251-261

Bleakley CM, Davison, GW. What is the biochemical and physiological rationale for using cold-water immersion in sports recovery? A systematic review. Br J Sports Med, 2010; 44: 179-187

Brindle TJ, Lebiedowska MK, Miller JL. Stanhope SJ. The influence of ankle joint movement on knee joint kinesthesia at various movement velocities. Scand J Med Sci Sports, 2010; 20: 262-267

Brindle TJ, Mizelle JC, Lebiedowska MK, Miller JL, Stanhope, SJ. Visual and proprioceptive feedback improves knee joint position sense. Knee Surg Sports Traumatol Arthrosc, 2009; 17: 40-47

Caraffa A, Cerulli G, Projetti M, Aisa G, Rizzo A. Prevention of anterior cruciate ligament injuries in soccer. A prospective controlled study of proprioceptive training. Knee Surg Sports Traumatol Arthrosc, 1996; 4(1): $19-21$ 
Chappell JD, Limpisvasti O. Effect of a neuromuscular training program on the kinetics and kinematics of jumping tasks. Am J Sports Med, 2008; 36(6): 1081-1086

Costello JT, Donnelly AE. Cryotherapy and joint position sense in healthy participants: a systematic review. $J$ Athl Train, 2010; 45: 306-316

Costello JT, Donnelly AE. Effects of cold water immersion on knee joint position sense in healthy volunteers. J Sports Sci, 2011; 29: 449-456

Docherty CL, Arnold BL. Force sense deficits in functionally unstable ankles. J Orthop Res, 2008; 26: 1489-1493

Dover G, Powers ME. Reliability of joint position sense and force-reproduction measures during internal and external rotation of the shoulder. J Athl Train, 2003; 38: 304-310

Dover G, Powers ME. Cryotherapy does not impair shoulder joint position sense. Arch Phys Med Rehabil, 2004; 85: 1241-1246

Drouin JM, Valovich-mcLeod TC, Shultz SJ, Gansneder BM, Perrin DH. Reliability and validity of the Biodex system 3 pro isokinetic dynamometer velocity, torque and position measurements. Eur J Appl Physiol, 2004; 91: 22-29

Dykstra JH, Hill HM, Miller MG, Cheatham CC, Michael TJ, Baker RJ. Comparisons of cubed ice, crushed ice, and wetted ice on intramuscular and surface temperature changes. J Athl Train, 2009; 44: 136-141

Furmanek MP, Słomka K, Juras G. The effects of cryotherapy on proprioception system. Biomed Res Int, 2014; 2014: $1-14$

Grob KR, Kuster MS, Higgins SA, Lloyd DG, Yata H. Lack of correlation between different measurements of proprioception in the knee. J Bone Joint Surg, 2002; 84: 614-618

Harriss DJ, Atkinson G. Ethical standards in sport and exercise science research. Int J Sports Med, 2013; 34: 1025-1028

Hart JM, Leonard JL, Ingersoll CD. Single-leg landing strategy after knee-joint cryotherapy. J Sport Rehabil, 2005; $14: 313-320$

Hewett TE, Ford KR, Myer GD. Anterior cruciate ligament injuries in female athletes: part 2, a meta-analysis of neuromuscular interventions aimed at injury prevention. Am J Sports Med, 2006; 34(3): 490-498

Hewitt BA, Refshauge KM, Kilbreath SL. Kinesthesia at the knee: the effect of osteoarthritis and bandage application. Arthritis Rheum, 2002; 47(5): 479-483

Holcomb WR. Duration of cryotherapy application. Hum Kinet ATT, 2005; 10: 60-62

Hopper D, Whittington D, Davies J, Chartier JD. Does ice immersion influence ankle joint position sense? Physiother Res Int, 1997; 2: 223-236

Hubbard TJ, Aronson SL, Denegar CR. Does cryotherapy hasten return to participation? A systematic review. J Athl Train, 2004; 39: 88-94

Hübscher M, Zech A, Pfeifer K, Hänsel F, Vogt L, Banzer W. Neuromuscular training for sports injury prevention: a systematic review. Med Sci Sports Exerc, 2010; 42: 413-421

Kennet J, Hardaker N, Hobbs S, Selfe J. Cooling efficiency of 4 common cryotherapeutic agents. J Athl Train, 2007; 42: 343-348

Khanmohammadi R, Someh M, Ghafarinejad F. The effect of cryotherapy on the normal ankle joint position sense. Asian J Sports Med, 2011; 2: 91-98

Knight KL. Cryotherapy in sport injury management. Human Kinetics, 1995

Knoop J, Steultjens MPM, van der Leeden M, van der Esch M, Thorstensson CA, Roorda LD, Lems WF,

Dekker J. Proprioception in knee osteoarthritis: a narrative review. Osteoarthritis Cartilage, 2011; 19: 381-388

Kynsburg A, Panics G, Halasi T. Long-term neuromuscular training and ankle joint position sense. Acta Physiol Hung, 2010; 97(2): 183-191

LaRiviere J, Osternig LR. The effect of ice immersion on joint position sense. J Sport Rehabil, 1994; 3: 58-67 
Laskowski ER, Newcomer-Aney K, Smith J. Proprioception. Phys Med Rehabil Clin N Am, 2000; 11(2): 323-40,

Lephart SM, Pincivero DM, Rozzi SL. Proprioception of the ankle and knee. Sports Med, 1998; 25: 149-155

Mandelbaum BR, Silvers HJ, Watanabe DS, Knarr JF, Thomas SD, Griffin LY, Garrett W. Effectiveness of a neuromuscular and proprioceptive training program in preventing anterior cruciate ligament injuries in female athletes: 2-year follow-up. Am J Sports Med, 2005; 33(7): 1003-1010

Myrer JW, Measom G, Fellingham GW. Temperature changes in the human leg during and after two methods of cryotherapy. J Athl Train, 1998; 33: 25-29

Oliveira R, Ribeiro F, Oliveira J. Cryotherapy impairs knee joint position sense. Int J Sports Med, 2010; 31: 198201

Olsson L, Lund H, Henriksen M, Rogind H, Bliddal H, Danneskiold-Samsøe B. Test-retest reliability of a knee joint position sense measurement method in sitting and prone position. Adv Physiother, 2004; 6: 37-47

Pincivero DM, Bachmeier B, Coelho AJ. The effects of joint angle and reliability on knee proprioception. Med Sci Sports Exerc, 2001; 33: 1708-1712

Proske U. What is the role of muscle receptors in proprioception? Muscle Nerve, 2005; 31: 780-787

Proske U. The role of muscle proprioceptors in human limb position sense: a hypothesis. J Anat, 2015; 227: 178-183

Proske U, Gandevia SC. The proprioceptive senses: their roles in signaling body shape, body position and movement, and muscle force. Physiol Rev, 2012; 92: 1651-1697

Richie DH, Functional instability of the ankle and the role of neuromuscular control: a comprehensive review. J Foot Ankle Surg, 2001; 40: 240-251

Riemann BL, Lephart SM. The sensorimotor system, part I: the physiologic basis of functional joint stability. J Athl Train, 2002a; 37: 71-79

Riemann BL, Lephart SM. The sensorimotor system, part II: the role of proprioception in motor control and functional joint stability. J Athl Train, 2002b; 37: 80-84

Roberts D, Ageberg E, Andersson G, Fridén T. Clinical measurements of proprioception, muscle strength and laxity in relation to function in the ACL-injured knee. Knee Surg Sports Traumatol Arthrosc, 2007; 15: 9-16

Rubley MD, Denegar CR, Buckley WE, Newell KM. Cryotherapy, sensation, and isometric-force variability. J Athl Train, 2003; 38: 113-119

Salles JI, Velasques B, Cossich V, Nicoliche E, Ribeiro P, Amaral MV, Motta G. Strength training and shoulder proprioception. J Athl Train, 2015; 50(3): 277-280

Selfe J, Callaghan M, McHenry A, Richards J, Oldham J. An investigation into the effect of number of trials during proprioceptive testing in patients with patellofemoral pain syndrome. J Orthop Res, 2006; 24: 12181224

Sherrington CS. The integrative action of the nervous system. New Haven, CT: Yale University Press, 1906

Shrout PE, Fleiss JL. Intraclass correlations: uses in assessing rater reliability. Psychol Bull, 1979; 86: 420-428

Smith TO, Davies L, Hing CB. A systematic review to determine the reliability of knee joint position sense assessment measures. Knee, 2013; 20: 162-169

Surenkok O, Aytar A, Tüzün E, Akman M. Cryotherapy impairs knee joint position sense and balance. Isokinet Exerc Sci, 2008; 16: 69-73

Swenson C, Swärd L, Karlsson J. Cryotherapy in sports medicine. Scand J Med Sci Sports, 1996; 6: 193-200

Taylor NAS, Sanders RH, Howick EI, Stanley SN. Static and dynamic assessment of the Biodex dynamometer. Eur J Appl Physiol, 1991; 62: 180-188

Thieme HA, Ozmun JC, Ingersoll CD, Knight KL. Cooling does not affect knee proprioception. J Athl Train, 1996; 31: 8-11

Tremblay F, Estephan L, Legendre M, Sulpher S. Influence of local cooling on proprioceptive acuity in the quadriceps muscle. J Athl Train, 2001; 36: 119-123 
Uchio Y, Ochi M, Fujihara A, Adachi N, Iwasa, J, Sakai Y. Cryotherapy influences joint laxity and position sense of the healthy knee joint. Arch Phys Med Rehabil, 2003; 84: 131-135

Warren TA, McCarty EC, Richardson AL, Michener T, Spindler KP. Intra-articular knee temperature changes: ice versus cryotherapy device. Am J Sports Med, 2004; 32: 441-445

Wassinger CA, Myers JB, Gatti JM, Conley KM, Lephart SM. Proprioception and throwing accuracy in the dominant shoulder after cryotherapy. J Athl Train, 2007; 42: 84-89

White GE, Wells GD. Cold-water immersion and other forms of cryotherapy: physiological changes potentially affecting recovery from high-intensity exercise. Extrem Physiol Med, 2013; 2: 26

Williams GN, Chmielewski T, Rudolph K, Buchanan TS, Snyder-Mackler L. Dynamic knee stability: current theory and implications for clinicians and scientists. J Orthop Sports Phys Ther, 2001; 31: 546-566

Zebis MK, Bencke J, Andersen LL, Døssing S, Alkjaer T, Magnusson SP, Aagaard P. The effects of neuromuscular training on knee joint motor control during sidecutting in female elite soccer and handball players. Clin J Sport Med, 2008; 18(4): 329-337

\section{Corresponding author:}

\section{Mariusz P. Furmanek,}

The Jerzy Kukuczka Academy of Physical Education in Katowice,

Department of Human Motor Behavior,

72A Mikolowska St, 40-065 Katowice, Poland,

Phone: +48 3220751 41,

Fax +48 3220752 00,

E-mail: m.furmanek@awf.katowice.pl 